\title{
Incidence and Prevalence of Amyotrophic Lateral Sclerosis in Canada: A Systematic Review of the Literature
}

\author{
C. Wolfson ${ }^{a, b}$ S. Kilborn ${ }^{a}$ M. Oskouic A. Genge ${ }^{c}$ \\ a Division of Clinical Epidemiology, McGill University Health Centre, and ${ }^{\mathrm{b}}$ Department of Epidemiology, \\ Biostatistics and Occupational Health and ${ }^{\mathrm{C}}$ Montreal Neurological Institute and Hospital, McGill University, \\ Montreal, Canada
}

\section{Key Words}

Amyotrophic lateral sclerosis $\cdot$ Motor neuron disease $\cdot$

Epidemiology $\cdot$ Incidence $\cdot$ Prevalence $\cdot$ Canada

\begin{abstract}
Background: Amyotrophic lateral sclerosis (ALS) is a fatal progressive neurodegenerative disease of unknown etiology. Although known to be rare, precise information on the frequency of ALS is essential to anticipate future demands on health resources and as baseline information for epidemiological studies. As part of a new ALS epidemiological initiative in Canada, we conducted a systematic review of published incidence and prevalence research in Canada. Methods: Electronic searches and bibliographic reviews of pertinent publications were conducted. Results: We identified 6 published studies from 4 Canadian provinces conducted between 1974 and 2004; 2 were available only as abstracts. Reported annual incidence rates were similar and study quality was generally good, but there was insufficient detail to adequately assess the methodological quality of 3 of the studies. The most recent studies reported an annual ALS age-adjusted incidence of 2.13 per 100,000 in Nova Scotia (2003-2004) and a crude mean annual incidence of 2.4 per 100,000 in Newfoundland and Labrador (2000-2004). Conclusions: There are limited data on the frequency of ALS
\end{abstract}

in Canada. We found no studies from 6 of the Canadian provinces or from the territories. Future research is needed to estimate the frequency of occurrence of ALS in Canada.

Copyright $\odot 2009$ S. Karger AG, Basel

\section{Introduction}

The health and economic burdens associated with amyotrophic lateral sclerosis (ALS) are devastating as ALS dramatically reduces the quality of life of affected persons and their families. Based on data from the Canadian Institute for Health Information, the direct costs of ALS to the Canadian economy were estimated to be CAD 13.8 million in 2000-2001, and mortality costs were CAD 168.6 million [1].

An essential component for studying the burden of disease is the availability of good quality information on the frequency of disease occurrence, both geographically and over time. Data on disease frequency in a population are used by government agencies to guide operational health policies, identify the need for health care services, and enable policy makers to forecast disease burden [2]. Understanding geographic and temporal variations in disease frequency can also provide clues about environmental exposures that may contribute to the development

\section{KARGER}

Fax +41613061234 E-Mail karger@karger.ch www.karger.com
(C) 2009 S. Karger AG, Basel

0251-5350/09/0332-0079\$26.00/0

Accessible online at:

www.karger.com/ned
Christina Wolfson

Division of Clinical Epidemiology, McGill University Health Centre

1025 Pine Avenue West, Suite P2.028, Montreal, QC, H3A 1A1 (Canada)

Tel. +1 514934 1934, ext. 44739, Fax +1 5149344458

E-Mail christina.wolfson@mcgill.ca 
of disease [3]. Studies that identify sub-populations or geographic clusters of individuals with an apparently increased risk of a disease often result in follow-up research to examine environmental agents that may explain these observations [4-6].

In a recent report, the World Health Organization (WHO) suggested that the global burden of neurological disorders has been seriously underestimated by traditional epidemiological and health statistical methods [7]. In the same report, the authors predict that the global aging of the population will result in an increase in the prevalence of neurological and other chronic diseases, for which current policy makers and health care providers may be unprepared. In 2007, the Canadian Brain and Nerve Health Coalition released the results of an analysis, which estimated the costs and health service's utilization for individuals suffering from any of a variety of neurological conditions [1]. Although various information sources were used, the authors note that there were insufficient data available to assess the full impact of most neurological diseases, including ALS, and subsequently called upon the research community for more research into this area [8].

The objective of the present inquiry was to prepare an inventory of, and to review, the published research on the incidence and prevalence of ALS in Canada. This project is the first phase in the development of a new epidemiological initiative for ALS in Canada: the Program in Epidemiology Targeting Amyotrophic Lateral Sclerosis (PETALS). The results of this review provide a baseline from which to suggest ALS research priorities in Canada.

\section{Background}

ALS is the most common form of progressive motor neuron disease (MND) and one of the most devastating neurological disorders. It is characterized by degeneration of lower and upper (corticospinal) motor neurons in the central nervous system, with bulbar involvement in about $20 \%$ of cases [9]. Selective and progressive motor neuronal cell death results in muscle weakness and wasting, and mortality typically results from respiratory paralysis a median of 3-5 years after diagnosis [10].

The etiology of ALS is unknown. The majority of ALS cases are sporadic, and only $5-10 \%$ of cases are considered to be familial $[10,11]$. Although a male predominance in disease incidence, ranging from around 1.5:1 to 1.8:1 has been previously noted [12], the validity of this finding has been questioned. Data from European population-based registers suggest the male:female ratio may be closer to 1:1 [13]. Greater incidences with increasing age have also been observed, but the age of peak incidence is not yet clear $[12,14]$. For several decades, there has been speculation that the incidence of MND, including ALS, may be increasing [15-17]. However, many of the studies that reported this were not population-based, and these findings may have been the result, at least in part, of improvements in diagnostic methods and case ascertainment [13]. Recent findings of an apparent increase in the risk of ALS in some population subgroups, such as professional soccer players $[18,19]$ and Gulf War veterans [20], have spurred a renewed interest in the study of ALS and putative environmental risk factors. Although a number of exogenous risk factors for ALS have been studied in the past, the results have been inconclusive [13].

To study disease incidence, the optimal approach is to conduct a prospective cohort study of disease-free individuals and monitor them for the occurrence of the disease of interest. Due to the rarity of ALS, however, this approach is not practical, and it has been estimated that a disease-free population of not less than a million would be needed to generate reliable incidence estimates [21]. The more practical approach is to systematically search for newly diagnosed cases in a particular population over a specified period of time. Difficulties related to incomplete case ascertainment, standardized use of diagnostic criteria, and defining the appropriate denominator for the incidence calculation (number of new cases/number of at-risk population) are inherent in studies of this type. While prevalence studies appear to be simpler to conduct, they too present many challenges. Prevalent cases are those individuals who have the disease at a particular point in time; point prevalence of ALS refers to the proportion of the population living with ALS at a point in time (i.e. on 'prevalence' day) regardless of when they were diagnosed, and period prevalence refers to the proportion of the population who have the disease over a period of time (often 1 year or more). Period prevalence estimates are larger than point prevalence estimates because they include prevalent cases at the beginning of the time period plus the new (incident) cases who have developed the disease during the study period [3]. Because a complete centralized registry for ALS does not exist in Canada, epidemiological studies often identify cases from community-based records (e.g. support groups), disease reporting by physicians, health care utilization data (emergency department visits, hospitalizations and drug use records), and even self-report. To ensure the most complete case ascertainment, multiple data sources 
should be searched, and then appropriate methods of statistical analyses should be used to produce reliable estimates [22].

\section{ALS Incidence and Prevalence Outside Canada}

Reported annual ALS incidence rates (per 100,000) in Europe, Asia, and North America, range from 2.1 (95\% CI, 1.8-2.4) in Israel to 8.5 (95\% CI, 6.1-11.6) in Middle Finland, age-adjusted to the 1990 US population [14]. However, the retrospective study design, as well as methodological differences across studies may have contributed to some of the observed variation. Incidence estimates that were most similar were from 4 prospective studies conducted in Scotland, Washington (USA), Ireland, and Piemonte (Italy), using similar methodologies. The age-adjusted annual incidence estimates (per $100,000)$ were very similar and ranged from $5.2(95 \% \mathrm{CI}$, 4.1-6.4) in Scotland to 6.0 (95\% CI, 5.1-6.9) in Ireland, suggesting a uniform frequency in Western countries [14]. Crude estimates of ALS incidence, per 100,000, were 2.24 in Scotland (1989) [23], 1.8 in Washington (USA, 1990-1995) [24], 2.1 in Ireland (1995-1997) [25], and 2.5 in Piemonte (Italy, 1995-1996) [14]. These estimates are also quite close to the crude incidence of 1.06 per 100,000, calculated from the southeast England ALS (SEALS) registry, which collected data in a similar prospective manner from 2002 to 2006 [26].

\section{ALS in Canada}

As a first step in our epidemiological research program on ALS in Canada, we conducted a systematic literature review of the published research on the incidence and prevalence of ALS in Canada.

\section{Methods}

Electronic searches were conducted in Medline and Embase from PubMed and Ovid, to identify published studies on the incidence and prevalence of ALS in Canada. Keywords searched were: 'amyotrophic lateral sclerosis' sequentially combined with 'Canada' and each of the Canadian provinces. Thirty-eight articles were returned from Ovid, and the abstracts of these articles were subsequently reviewed. Only 3 publications were judged to be relevant to this systematic review [27-29]. Of the 35 excluded articles, 16 concerned the debate regarding assisted suicide and euthanasia [30], 5 were related to the measurement of biochemical parameters in ALS, 4 discussed clinical practice and disease management, 3 described ALS outside Canada, there was 1 case study and 2 publications each on qualitative studies, the genetics of ALS, and ALS disease characterization. By searching the bibliographies of the 3 relevant papers, 2 additional references [31, 32], published only as abstracts, were identified (table 1; fig. 1).
ALS is also known as 'Lou Gehrig's disease' in North America, and is one of the diseases included in the overarching diagnostic category of MND. For this reason, we conducted the same searches substituting these alternate terms. As a result 2 additional references on MND were identified, but only 1 was included [33]. The second was excluded because the primary aim of the study was the estimation of the prevalence of affective disorder within the MND population, and the authors did not present sufficient analysis of the MND data to be included in this review.

Since we anticipated that there would be few publications on ALS frequency in Canada, inclusion criteria were intentionally broad. Publications which reported primary data on the incidence or prevalence of ALS or MND in Canada were included. We report the estimated crude and age-adjusted (when available) annual incidence rates along with 95\% CI. When CI were not provided, we computed them assuming that the observed counts followed a Poisson distribution [34]. While our primary aim was to assemble an inventory of studies, we also assessed the methodological quality by having 2 reviewers (C.W. and S.K.) independently review each publication using a quality assessment grid that contained parameters relevant to epidemiological research. These included appropriate diagnostic criteria, completeness of case ascertainment, identification of potentially missed cases, age-adjustment, comparability of data, and other elements related to the study design.

\section{Results}

We identified 5 studies reporting on the incidence of ALS in 3 Canadian provinces. The point prevalence of ALS was also reported in 1 of the 5 studies (table 1). We also identified 1 study which reported on the point, and the 2-year period, prevalence of MND in Alberta (table 2). Two of the incidence studies were available as abstracts $[31,32]$ only, and the earliest study from Nova Scotia [29] provided an overview of the sources they had searched and little further detail. For this reason, we were unable to fully assess the quality of the methods used in these 3 studies. For the remaining 3 studies, we found the methodological quality to be good.

\section{Incidence of ALS in Nova Scotia}

Three publications emanating from an overlapping group of researchers assessed the incidence of ALS in Nova Scotia. The earliest appeared in 1987 [29] and was a retrospective study. Clinically definite cases of ALS in Nova Scotia were identified between January 1, 1974 and December 30,1984, by contacting all provincial clinical neurologists, neurosurgeons, physiatrists, and neuropathologists, as well as searching the records of the major provincial referral medical institutions. Using this approach, 169 cases were identified, resulting in a mean annual crude incidence rate of 1.95 per 100,000 over the 11 
Table 1. Comparison of incidence and prevalence studies of ALS in Canada

\begin{tabular}{|c|c|c|c|c|c|c|c|}
\hline & Province & Period studied & Case ascertainment method & $\begin{array}{l}\text { Diagnostic } \\
\text { criteria }\end{array}$ & $\begin{array}{l}\text { Crude inci- } \\
\text { dence per } \\
100,000\end{array}$ & $\begin{array}{l}\text { Age-adjusted } \\
\text { incidence per } \\
100,000\end{array}$ & $\begin{array}{l}\text { Point pre- } \\
\text { valence per } \\
100,000\end{array}$ \\
\hline $\begin{array}{l}\text { Murray } \\
\text { et al. [29] }\end{array}$ & $\begin{array}{l}\text { Nova } \\
\text { Scotia }\end{array}$ & $\begin{array}{l}\text { January } 1, \\
1974 \text { to } \\
\text { December } 30 \text {, } \\
1984\end{array}$ & $\begin{array}{l}\text { retrospective data collection: } \\
\text { records searched at all major referral } \\
\text { medical institutions in the province: } \\
\text { hospitals and rehabilitation centers, } \\
\text { laboratory records at EMG laboratories; } \\
\text { cooperation of all neurologists, neuro- } \\
\text { surgeons, physiatrists, and neuropathologists }\end{array}$ & $\begin{array}{l}\text { clinically } \\
\text { definite ALS; } \\
\text { no further } \\
\text { information } \\
\text { provided }\end{array}$ & $\begin{array}{l}1.95 \\
(1.0-2.9)^{2}\end{array}$ & $\begin{array}{l}2.22^{1} \\
(0.13-4.32)\end{array}$ & n.a. \\
\hline $\begin{array}{l}\text { Murray and } \\
\text { Traynor [31] } \\
\text { (abstract only) }\end{array}$ & $\begin{array}{l}\text { Nova } \\
\text { Scotia }\end{array}$ & 1995 & $\begin{array}{l}\text { case-ascertainment not described; } \\
\text { authors stated that identical methods } \\
\text { were used as the } 1984 \text { Nova Scotia study }\end{array}$ & not specified & $\begin{array}{l}2.03 \\
(1.2-3.2)^{2}\end{array}$ & $\begin{array}{l}2.3^{1} \\
(0.08-4.53)\end{array}$ & n.a. \\
\hline $\begin{array}{l}\text { Bonaparte } \\
\text { et al. [27] }\end{array}$ & $\begin{array}{l}\text { Nova } \\
\text { Scotia }\end{array}$ & $\begin{array}{l}\text { March } 1,2003 \\
\text { to February } \\
28,2004\end{array}$ & $\begin{array}{l}\text { prospective data collection: } \\
\text { participation of all neurologists and } \\
\text { physiatrists in Nova Scotia; contacted by } \\
\text { telephone, email, letter; } \\
\text { clinician datasheets submitted, retrospective } \\
\text { data collection; } \\
\text { Medical Services Insurance database, } \\
\text { ICD9-CM diagnostic code } 335.20\end{array}$ & El Escorial & $\begin{array}{l}2.24 \\
(1.28-3.2)^{2}\end{array}$ & $\begin{array}{l}2.13 \\
(0.11-4.15)\end{array}$ & n.a. \\
\hline $\begin{array}{l}\text { Hudson } \\
\text { et al. [28] }\end{array}$ & Ontario & $1978-1982$ & $\begin{array}{l}\text { retrospective data collection: } \\
\text { hospital records; } \\
\text { ALS clinic in London; } \\
\text { ALS case-registry of ALS Society of Canada; } \\
\text { mortality data from death certificates in } \\
\text { Provincial Registrar's Office }\end{array}$ & $\begin{array}{l}\text { progressive } \\
\text { muscle wasting, } \\
\text { fasciculation, } \\
\text { pyramidal signs } \\
\text { without sensory } \\
\text { changes }\end{array}$ & $\begin{array}{l}1.63 \\
(0.17-3.09)\end{array}$ & $\begin{array}{l}2.0 \text { (women) } \\
2.6 \text { (men) }\end{array}$ & $\begin{array}{l}4.9 ; \\
\text { Jan } 1,1983\end{array}$ \\
\hline $\begin{array}{l}\text { Stefanelli } \\
\text { et al. [32] } \\
\text { (abstract only) }\end{array}$ & $\begin{array}{l}\text { New- } \\
\text { foundland } \\
\text { and } \\
\text { Labrador }\end{array}$ & $\begin{array}{l}\text { January } 2000 \\
\text { to December } \\
2004\end{array}$ & $\begin{array}{l}\text { Retrospective data collection: } \\
\text { records searched of all } 3 \text { provincial centers } \\
\text { with neurologist representation and electro- } \\
\text { physiological capabilities; } \\
\text { cross-referenced with provincial riluzole } \\
\text { prescriptions }\end{array}$ & not specified & $\begin{array}{l}2.4 \\
(1.9-3.1)\end{array}$ & n.a. & n.a. \\
\hline
\end{tabular}

Figures in parentheses are 95\% CI.

${ }^{1}$ Figures were presented in Bonaparte et al, 2007; they were not presented in original publication.

${ }^{2}$ CI calculated assuming a Poisson distribution for the observed cases.

Table 2. Prevalence of MND in Alberta

\begin{tabular}{|c|c|c|c|c|c|c|c|}
\hline & Province & Years studied & $\begin{array}{l}\text { Case ascertainment } \\
\text { method }\end{array}$ & $\begin{array}{l}\text { Diagnostic } \\
\text { criteria }\end{array}$ & $\begin{array}{l}\text { Point } \\
\text { prevalence }\end{array}$ & $\begin{array}{l}\text { Crude period } \\
\text { prevalence } \\
\text { per } 100,000\end{array}$ & $\begin{array}{l}\text { Age-adjusted } \\
\text { period prevalence } \\
\text { per } 100,000\end{array}$ \\
\hline $\begin{array}{l}\text { Svenson } \\
\text { et al. [33] }\end{array}$ & Alberta & $\begin{array}{l}\text { January } 1,1994 \\
\text { to December } 31 \\
1995\end{array}$ & $\begin{array}{l}\text { retrospective data collection; } \\
\text { administrative database: Alberta } \\
\text { Health Care Insurance Plan; } \\
\text { select ICD-9 code No. } 335.2\end{array}$ & $\begin{array}{l}\text { MND; ICD-9 } \\
\text { code } 335.2\end{array}$ & $\begin{array}{l}6.07 ; \\
\text { January 1, } 1995\end{array}$ & n.a. & $\begin{array}{l}\text { 7.38; } \\
1994 \text { and } 1995\end{array}$ \\
\hline
\end{tabular}

years of the study. A peak annual incidence of 2.66 per 100,000 was reported for 1981. Beyond a brief listing of the information sources that were searched, very little methodological detail was presented.
The second ALS incidence publication from Nova Scotia was only available in abstract form [31]. Data were collected during 1995, and the authors stated that their methodology was identical to a previous 1974-1984 study 


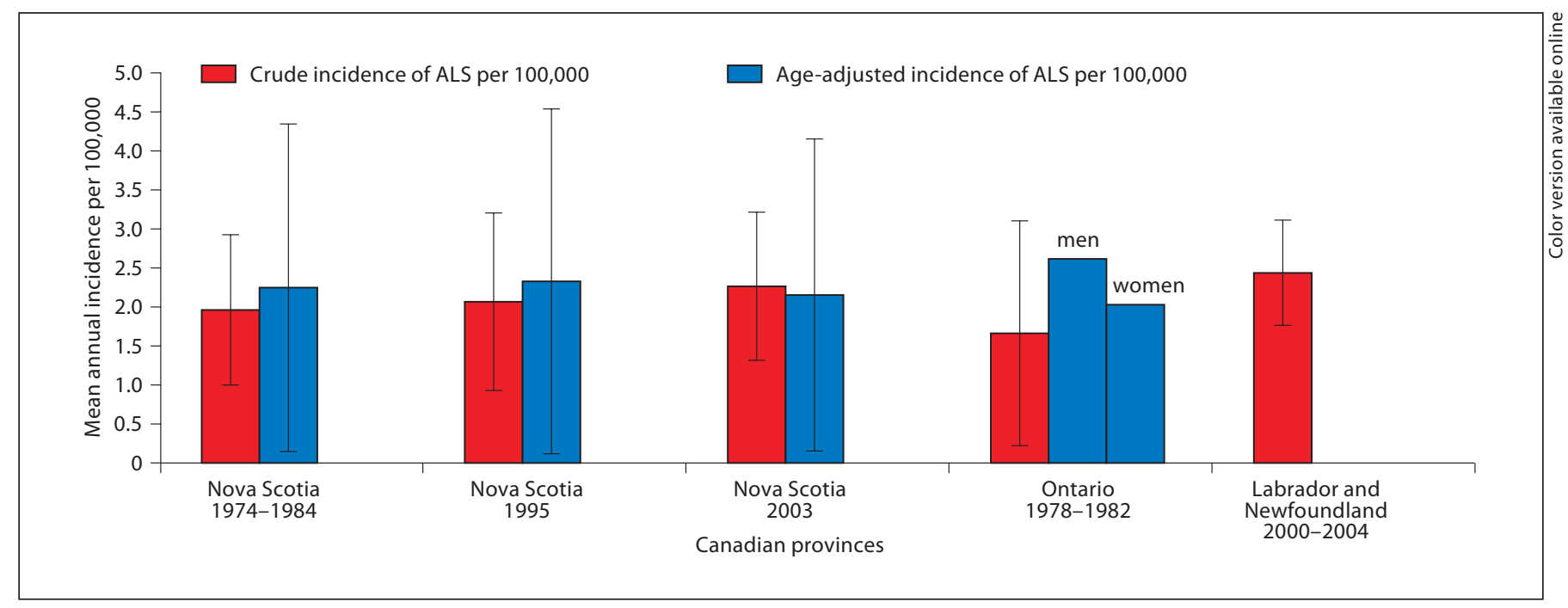

Fig. 1. ALS incidence reported in 3 Canadian provinces over a 31-year period. Crude incidence rates, age-adjusted incidence rates, and 95\% CI are presented where available. 95\% CI were calculated for the crude incidence rates in Nova Scotia, 1974-1984, 1995, and 2003, based on data provided in the publication assuming a Poisson distribution for the observed cases.

(described above). Crude ALS incidence in 1995 was reported to be 2.03 per 100,000 .

The most recent study from Nova Scotia was published in 2007 [27] and was judged to be of high methodological quality. The authors estimated the annual incidence of ALS using data collected in 2003, and compared this estimate to the incidence figures from the 2 previous studies conducted in Nova Scotia. All newly diagnosed cases in the province were identified over a 1-year (2003) period, using a population-based prospective design. Persons over 18 years who had received a diagnosis of ALS using the El Escorial criteria [35] were included. By surveying all neurologists and physiatrists in the province, asking them to submit monthly datasheets on newly diagnosed ALS cases, and subsequently contacting physicians to confirm submitted datasheets, investigators determined that 21 new cases of ALS had been diagnosed in Nova Scotia during 2003. The corresponding estimated annual crude incidence rate was 2.24 per 100,000 , and the age-adjusted rate was 2.13 per 100,000 (95\% CI, 0.114.15; adjusted to 2001 Canadian census data [36]). These prospective estimates were reported by the authors to be in agreement with the incidence rates of 2.44 per 100,000 (95\% CI, 0.27-4.6) determined retrospectively for the same study period using data from the provincial Medical Services Insurance database.
As noted, a second goal of this study was a comparison of the incidence of ALS in Nova Scotia over time. To enhance the comparability of the estimates, the authors computed age-adjusted incidence estimates for the 2 earlier studies, which were not presented in the original publications $[29,31]$. The age-adjusted mean annual ALS incidence rates (per 100,000) ranged from 2.22 (95\% CI, 0.13-4.32) for the 1974-1984 study [29] to 2.3 (95\% CI, $0.08-4.53)$ in 1995 [31], and 2.13 (95\% CI, 0.11-4.15) in 2003 [27]. These results suggest that the incidence of ALS in Nova Scotia has remained relatively stable over this 30year period.

\section{Incidence and Prevalence of ALS in Ontario}

Our search identified 1 study reporting on ALS incidence and prevalence in Ontario. Using a retrospective study design, Hudson et al. [28] examined 12 counties in southwestern Ontario between the years 1978 and 1982. Cases were ascertained from several sources including hospital charts in 16 hospitals, clinical records at the ALS Clinic at the University Hospital in London, Ontario, and a self-report registry maintained by the ALS Society of Canada. The authors state that 'diagnostic criteria included progressive muscular wasting, fasciculation, and pyramidal signs, without sensory changes, as included under the diagnostic terms MND, progressive bulbar palsy, progressive muscular atrophy, or ALS'. The mean 
crude annual incidence rate over the 5 -year period was 1.63 per 100,000 population (95\% CI, $0.17-3.09)$. Age-adjusted incidence rates per 100,000 were 2.6 for men and 2.0 for women. The authors further reported that there were 83 people living with ALS in southwestern Ontario on January 1,1983 , resulting in a point prevalence of 4.9 per 100,000 persons.

\section{Incidence of ALS in Newfoundland and Labrador}

One publication reporting on the incidence of ALS in Newfoundland and Labrador was identified, but the report was only available as an abstract [32] and thus we were not able to adequately assess methodological quality due to lack of information. Cases of ALS were retrospectively identified for a 5-year period from 2000 to 2004, inclusive, from all 3 provincial centers with neurologist representation and electrophysiological capabilities. These cases were then cross-referenced with a voluntary case registry from the ALS Society and provincial riluzole (a pharmaceutical commonly prescribed for ALS) prescriptions. Over the 5year period, the mean annual crude incidence was estimated to be 2.4 per 100,000 (95\% CI, 1.9-3.1), with the peak incidence in 2001 of 3.3 per 100,000.

\section{Prevalence of MND in Alberta}

Two studies with reports of the prevalence of MND in Alberta were identified in our search, but only 1 was included in this review. As noted, the primary objective of the excluded study was the prevalence of affective disorder in MND, not the prevalence of MND in Alberta. The included study, published in 1999 [33], was a populationbased study carried out between January 1, 1994 and December 31, 1995 to estimate the 2-year period prevalence of MND in Alberta. Investigators identified individuals with the ICD-9 diagnostic code for MND (no. 335.2) in the Alberta Health Care Insurance Plan (AHCIP) database, a fee-for-service practitioner claims administrative database.

Over the 2-year period (1994-1995), 208 cases of MND were identified yielding a crude period prevalence of 7.38 (8.9 for men, 5.9 for women) per 100,000 population. The point prevalence of MND was 6.07 (7.31 for men, 4.84 for women) per 100,000 on July 1, 1995.

\section{Discussion}

We identified only 6 studies reporting on the incidence or prevalence of ALS or MND in Canada, which were published in the last two decades [27-29, 31-33].
Three of the 5 incidence studies were conducted in Nova Scotia, and involved some of the same researchers over time. This is important from two perspectives. The first is that this allows for comparison across these studies over time since a similar methodology was used, and secondly this means that there is a history of strength in ALS epidemiological research in Nova Scotia. One study each on ALS incidence was identified from Ontario [28] and Newfoundland and Labrador [32], and 1 study of MND prevalence was published using data from the Alberta Health Care Utilization Database [33]. Of the 6 reports, 2 were published only in abstract form [31,32] and never appeared in peer-reviewed journals, and the earliest study from Nova Scotia [29] provided little methodological detail. This made it difficult to judge the adequacy of the methodology of these studies. Despite a thorough search of the literature, no published studies were found with estimates of the incidence or prevalence of ALS in 6 of the Canadian provinces or the territories.

We were only able to assess the methodological quality of 3 of the 6 studies. We found all of these studies to be of acceptable methodological quality with the 2 most recent being the most methodologically sound. Our present knowledge of the incidence and prevalence of ALS in Canada is heavily influenced by the strengths and limitations of these 6 published studies. It is thus important to consider in more general terms the methodological strengths and challenges, to better understand the difficulty in carrying out these studies, and as an indicator of the quality of the results.

\section{Age-Adjustment and Comparability of Data}

To enhance comparability of prevalence and incidence estimates from populations with different age distributions, estimates should be age-adjusted to a common population. Crude incidence rates of ALS in Canada ranged from a low of 1.63 in Ontario 1978-1982 [28] to 2.4 in Newfoundland and Labrador 2000-2004 [32]. Age-adjusted rates were presented for Ontario [28] and for all 3 Nova Scotia studies [27, 29, 31], but were not available for the Newfoundland and Labrador study [32]. Since all studies included in the present review were conducted in Canada, and adjustments were made using Canadian Census population data, it is reasonable to compare the age-adjusted rates. Despite differences in methodology used, location, and time of the study, age-adjusted incidence rates (per $100,000)$ were similar, and in line with what has been reported in the published literature [21]. They ranged from 2.13 (95\% CI, 0.11-4.15) in Nova Scotia in 2003 [27] to 2.3 (95\% CI, 0.08-4.53) in Nova Scotia in 1995 [31]. 
From our study, data on the prevalence of ALS in Canada are even more scarce than incidence data, with only 1 publication from Alberta and a single reported estimate within the Ontario incidence study. In southwestern Ontario [28], the estimated point prevalence on January 1 , 1983 was 4.9 per 100,000. The Alberta MND study [33] reported a point prevalence of 6.07 per 100,000 on January 1,1995 . Since MND is a diagnostic umbrella term, under which several neurodegenerative disorders including ALS are included, it is not surprising the estimated prevalence of MND would be higher than for ALS. The 2 -year age-adjusted period prevalence of MND in Alberta was 7.38 per 100,000 in 1994-1995.

\section{Prospective versus Retrospective Data Collection}

Only 1 of the Canadian studies [27] was prospective and the other 5 used retrospective data collection. Nevertheless, both Bonaparte et al. [27] and Murray et al. [29] conducted sub-analyses comparing retrospective and prospective estimates to validate their findings, and both reported that the two estimates were similar (although Murray et al. [29] did not provide the incidence estimate from their prospective 'validation' data). While the Canadian incidence estimates are lower than those obtained in prospective studies done elsewhere [14], the CI overlap.

\section{Appropriate Diagnostic Criteria}

The use of standardized criteria to identify disease cases is critical if meaningful comparisons are to be made between disease rates reported from different studies. At present, the gold standard for diagnosing ALS are the El Escorial criteria, which were endorsed by the World Federation of Neurology in 1994 [37], and underwent slight modifications in 1998 [35]. Only 1 of the 6 studies reported using the El Escorial criteria [27]. The criteria used to confirm the definite clinical diagnosis of ALS were not provided in the publication from Newfoundland and Labrador [32] nor in the 1996 Nova Scotia publication [31]. The first Nova Scotia study [29] was conducted before the criteria were endorsed. The authors note that individuals with clinically definite ALS were included, but with no further information provided. The 1986 Ontario publication was also conducted pre-El Escorial Criteria, and a definite diagnosis of ALS was based on the presence of progressive muscular wasting, fasciculation, and pyramidal signs, without sensory changes, which the authors note were the standard diagnostic criteria at the time.
Differences in diagnostic criteria as well as in the standards for the assignment of codes over time, and between studies will certainly affect the numbers of cases identified, and present challenges to making comparisons across studies. Even as recently as 2007 , the revised criteria for ALS had not been universally adopted into practice, and some patients were still diagnosed using the old criteria [13]. Although the impact of the evolving diagnostic criteria on case ascertainment has not been examined, it is important to recognize the potential impact of case misclassification (i.e. inclusion of cases who do not have ALS and exclusion of cases who do). These uncertainties make it difficult to conclude if apparent changes in disease incidence are due to actual increase, changes in coding practices, improvements in diagnosis, or some combination thereof [6]. Finally, since there is no definitive test to confirm ALS, the validity of the diagnosis is dependent on the training and clinical judgment of the attending clinician [13].

The prevalence study of MND from Alberta [33] identified cases by searching the AHCIP database for the corresponding ICD-9 diagnostic code. The most recent Nova Scotia study [27] also used ICD-9 codes contained in the provincial health care database to obtain an incidence estimate for comparison with the one obtained through the prospective study. Both studies collected data after the endorsement of the El Escorial diagnostic criteria in 1994 [37] and used the appropriate diagnostic code to conduct their searches (ICD-9 335.2 for MND or 335.20 for ALS). However, the assignment of ICD-9 codes does not explicitly give information about which criteria were used by the diagnosing physician.

The use of ICD codes for disease identification in epidemiological research can be problematic. Kelsey et al. [2] caution that changes in conventions for the assignment of diagnostic codes have been observed in some diseases, and researchers should be aware of the potential for inaccurate code assignment by physicians. The findings of a database validation study that was conducted on the Veteran's Association (VA) ALS database in the United States [38] highlight the need to interpret database-derived epidemiological data with caution. The publication reported over half of the people with an ICD-9 code for ALS or MND in the VA database were found to not have the disease, using screening by self-report followed by medical records review as the gold standard. Bonaparte et al. [27] noted that it was possible that false-positive cases may have also been present in the database they used, because the ICD-9 code may have been assigned to tentative or uncertain diagnoses. 


\section{Completeness of Case Ascertainment}

In addition to diagnostic uncertainty, concern about the completeness of case ascertainment in the study of disease frequency is a common challenge in epidemiological research. A population registry which includes reported new cases is one of the most complete sources from which to obtain data about the frequency of a disease. However, these are labor-intensive and costly to maintain, and are not available for all diseases. There have been successful efforts to establish ALS registries in other parts of the world. The previously described SEALS registry [26] in southeast England is also part of EURALS, which is a consortium of population-based ALS registries from Italy, Scotland, Ireland, and England, as well as clinic-based cohorts from Russia, Serbia, London, Madrid, Limonges, and Israel [39]. In the United States, the National Registry of Veterans with ALS [38] has attempted to identify all veterans with ALS nationally since 1993, and as of 2007 had enrolled over 2,000 registrants and banked over 1,000 DNA samples. Campaigning from the non-veteran ALS population in the USA, by researchers, clinicians, patients, and the US ALS Association, has recently led to the approval of an unprecedented legislation, requiring the Centers for Disease Control to establish a national registry to collect data on ALS by 2011 [40]. This registry will represent a unique opportunity to study ALS on a national scale in the USA.

In Canada, a comprehensive registry for ALS does not exist. In the absence of a disease registry, researchers should aim to identify newly diagnosed individuals from multiple sources to obtain the most complete case ascertainment. This strategy is not perfect; some cases will inevitably be missed, and others may be counted more than once if they are captured in more than one source. In order to provide readers with a basis for judging the quality and applicability of published incidence and prevalence figures, researchers should consider the use of capturerecapture methods to estimate the extent of incomplete case ascertainment based on the number of overlapping (double-counted) cases that occur when multiple sources are searched [22].

All 5 ALS studies used multiple sources to identify people with the disease. Relevant clinical specialists were contacted [27] and records were reviewed [29] in the studies from Nova Scotia. As previously mentioned, the Nova Scotia studies conducted a 'validation analysis', and the authors concluded that they had reasonably complete case ascertainment based on similarity between the incidence estimates calculated from both retrospective and prospective data collected for the same period. Sixteen hospitals, 1 clinic and a partially complete case registry were examined to identify people with ALS in southwestern Ontario. In Newfoundland and Labrador, data were collected from records reviews and from provincial riluzole prescriptions. However, neither of the publications contains an estimate of what percentage of hospitals and clinics were represented in their samples. Although all 5 ALS studies used multiple data sources for case ascertainment, none provided information to estimate the percentage of available sources that were searched, and none employed capture-recapture methodology to estimate the undercount.

The Alberta MND prevalence study collected information from a single source, the provincial health care utilization database (AHCIP), to identify people in the province with MND. Registration in the AHCIP is mandatory for all Alberta residents; therefore, the database should contain all cases seen by a physician in Alberta. This presumes that physicians submit billing claims to the AHCIP, and are reasonably accurate in their diagnosis. As far as we are aware, however, there have been no published studies to estimate the false-positive and falsenegative rates for MND using the AHCIP. To be included in the database a person with a particular diagnosis needs to visit a medical professional in the years being studied. Given the obvious and often progressive symptoms associated with most MND, it is likely that individuals suffering from MND would seek medical attention at some point. The MND point prevalence in Alberta in 1995, of 6.07 per 100,000 , is higher than internationally reported estimates. In fact, it was cited as the highest reported prevalence rate for MND in Europe and North America in the 1990s [41]. However, making meaningful comparisons between MND data that were collected using different study methodologies is challenging, for the same reasons as previously described for comparing ALS data. Most notably for the MND data from Alberta, we were unable to find any studies on the accuracy of the AHCIP database. Additionally, it is difficult to interpret comparisons between crude data, age-adjusted data, and data that have been age-adjusted to different populations.

In the context of the present review, perhaps the most important limitations to comparing the Alberta data to rest of Canada was that the main inclusion criterion was a diagnosis of MND and not specifically ALS. As previously noted, the corresponding ICD-9 coding includes the diagnoses of ALS, primary lateral sclerosis, progressive muscular atrophy, pseudobulbar palsy, and progressive bulbar palsy. Spinal muscular atrophy may also 
be considered a form of MND, although it is listed separately in the ICD-9 coding. As a result, one would expect the prevalence of MND to exceed the prevalence of ALS.

\section{Conclusion}

The data available to date on the incidence and prevalence of ALS in Canada come from a few studies, from only 4 provinces, representing only a small portion of Canada's population. Some were published before the present ALS diagnostic criteria were implemented, and some provided insufficient detail to adequately evaluate the methodology used [29]. Two studies were reported only in abstract form [31,32], and it was not possible to assess the quality of the methods. None of the studies included a discussion or estimation of potentially missed cases, which is essential to assess the completeness of case ascertainment. The rarity of ALS combined with its short life expectancy and, until fairly recently, limited public awareness makes it a challenging disease for epidemiological study. The existence of 3 studies from Nova Scotia, 1 in each decade since the 1980s, is a testament to the dedication of the research community in this province, and the most recent publication [27] is current and of good quality. Further studies of good quality are needed in all of Canada's provinces and territories to precisely characterize the incidence and prevalence of ALS.

\section{Acknowledgments}

This project was carried out at the Research Institute of the McGill University Health Centre, which is supported in part by the Fonds de la Recherche en Santé du Québec. This work was funded, in part, through a Pilot Project grant from the Research Institute of the McGill University Health Centre. The authors also thank Bin Zhu for statistical advice and for computing the confidence intervals when needed.

\section{References}

1 Canadian Institute for Health Information: The Burden of Neurological Diseases, Disorders, and Injuries in Canada. Ottawa/Ontario, Canadian Institute for Health Information, 2007.

2 Kelsey JL, Whittemore AS, Alfres AS, Thompson WD: Methods in Observational Epidemiology. New York, Oxford University Press, 1996

3 Koepsell TD, Weiss NS: Epidemiologic Methods: Studying the Occurrence of Illness. New York, Oxford University Press, 2003.

-4 Kalfakis N, Vassilopoulos D, Voumvourakis C, Ndjeveleka M, Papageorgiou C: Amyotrophic lateral sclerosis in southern Greece: an epidemiologic study. Neuroepidemiology 1991; 10:170-173.

-5 Scott KM, Abhinav K, Stanton BR, et al: Geographical clustering of amyotrophic lateral sclerosis in south-east England: a population study. Neuroepidemiology 2009;32:81-88.

-6 Stallones L, Kasarskis EJ, Stipanowich C, Snider G: Secular trends in mortality rates from motor neuron disease in Kentucky 1964-1984. Neuroepidemiology 1989;8:6878.

7 Murray CJL, Lopen AD: The Global Burden of Diseases: A Comprehensive Assessment of Mortality and Disability from Diseases, Injuries and Risk Factors in 1990 and Projected to 2020. Global Burden of Diseases and Injury Series, vol 1. Cambridge, Harvard School of Public Health, 1996.
-8 Tator C, Bray G, Morin D: The CBANCH report: the burden of neurological diseases, disorders, and injuries in Canada. Can J Neurol Sci 2007;34:268-269.

9 Aminoff MJ, Greenberg DA, Simon RP: 16 Hojer-Pedersen E, Christensen PB, Jensen Clinical Neurology, ed 6. New York, McGraw-Hill, 2005.

10 Brown RH: Amyotrophic lateral sclerosis and other motor neuron diseases; in Kasper DL, Braunwald E, Fauci AS, Longo DL, Jameson L, Isselbacher KJ (eds): Harrison's Internal Medicine. New York, McGraw-Hill, 2005.

11 Valdmanis PN, Rouleau GA: Genetics of familial amyotrophic lateral sclerosis. Neurology 2008;70:144-152.

12 Yoshida S, Mulder DW, Kurland LT, Chu CP, Okazaki H: Follow-up study on amyotrophic lateral sclerosis in Rochester, Minn., 1925 through 1984. Neuroepidemiology 1986;5: 61-70.

13 Logroscino G, Traynor BJ, Hardiman O, Chio' A, Couratier P, Mitchell JD, Swingler RJ, Beghi E: Descriptive epidemiology of amyotrophic lateral sclerosis: new evidence and unsolved issues. J Neurol Neurosurg Psychiatry 2008;79:6-11.

14 Piemonte and Valle d'Aosta Register for Amyotrophic Lateral Sclerosis (PARLAIS): Incidence of ALS in Italy: evidence for a uniform frequency in Western countries. Neurology 2001;56:239-244.
15 Angelini C, Mario A, Bresolin N: Incidence and prevalence of motor neuron disease in two Danish counties. Neuroepidemiology 1989;2:236-242. NB: Incidence and prevalence of motor neuron disease in two Danish counties. Neuroepidemiology 1989;8:151-159.

17 Kahana E, Zilber N: Changes in the incidence of amyotrophic lateral sclerosis in Israel, Arch Neurol 1984;41:157-160.

18 Chio A, Benzi G, Dossena M, Mutani R, Mora G: Severely increased risk of amyotrophic lateral sclerosis among Italian professional football players. Brain 2005; 128 : 472-476.

19 Taioli E: All causes mortality in male professional soccer players. Eur J Public Health 2007; 17:600-604.

20 Institute of Medicine: Amyotrophic Lateral Sclerosis in Veterans: Review of the Scientific Literature. Washington, National Academic Press, 2006.

21 Cronin S, Hardiman O, Traynor BJ: Ethnic variation in the incidence of ALS: a systematic review. Neurology 2007;68:1002-1007.

22 Hooke EB, Regal RR. Capture-recapture methods in epidemiology: methods and limitations. Epidemiol Rev 1995; 17:243-264.

23 The Scottish Motor Neuron Disease Register: a prospective study of adult onset motor neuron disease in Scotland. Methodology, demography and clinical features of incident cases in 1989. J Neurol Neurosurg Psychiatry 1992;55:536-541. 
-24 McGuire V, Longstreth WT Jr, Koepsell TD, van Belle G: Incidence of amyotrophic lateral sclerosis in three counties in western Washington state. Neurology 1996;47:571573.

-25 Traynor BJ, Codd MB, Corr B, Forde C, Frost E, Hardiman O: Incidence and prevalence of ALS in Ireland, 1995-1997: a populationbased study. Neurology 1999;52:504-509.

-26 Abhinav K, Stanton B, Johnston C, et al: Amyotrophic lateral sclerosis in south-east England: a population-based study. The South-East England Register for Amyotrophic Lateral Sclerosis (SEALS Registry). Neuroepidemiology 2007;29:44-48.

-27 Bonaparte JP, Grant IA, Benstead TJ, Murray TJ, Smith M: ALS incidence in Nova Scotia over a 20-year-period: a prospective study. Can J Neurol Sci 2007;34:69-73.

28 Hudson AJ, Davenport A, Hader WJ: The incidence of amyotrophic lateral sclerosis in southwestern Ontario, Canada. Neurology 1986;36:1524-1528.

-29 Murray TJ, Cameron J, Heffernan LP, MacDonald HN, King DB, Bedwell SR, Scott M, Patil J, Shears A, Malik HG: Amyotrophic lateral sclerosis in Nova Scotia. Adv Exp Med Biol 1987;209:345-349.
30 Canada Supreme Court: Rodriguez v. British Columbia (Attorney-General). Can Supreme Court Rep Can Supreme Court 1993;3:519632.

31 Murray TJ, Traynor J: Incidence of ALS in Nova Scotia. Int Alliance ALS/MND Assoc 7th Int Symp, Chicago, 1996.

32 Stefanelli M, Lim C, Sloka J, Whelan G, Murphy D, Goodridge A, et al: Iron horse disease: are we overrun? The incidence of ALS in Newfoundland and Labrador, Canada. Abstracts XVIII World Congr Neurol, Sydney, 5-11 November 2005, S1:526.

33 Svenson LW, Cwik VA, Martin WR: The prevalence of motor neuron disease in the Province of Alberta. Can J Neurol Sci 1999, 26:119-122.

34 Lilienfeld DE, Stolley PD: Foundations of Epidemiology, ed 3. Oxford, Oxford University Press, 1994.

-35 Brooks B, Miller RG, Swash M, Munsat TL, World Federation of Neurology Research Group on Motor Neuron Diseases: El Escorial Criteria revisited: revised criteria for the diagnosis of amyotrophic lateral sclerosis. Amyotroph Lateral Scler Other Motor Neuron Disord 2000;1:293-299.
36 Statistics Canada: Population and Dwelling Counts, for Canada, Provinces and Territories, 2001 and 1996 Censuses. Ottawa, Statistics Canada.

37 Brooks BR: El Escorial World Federation of Neurology criteria for the diagnosis of amyotrophic lateral sclerosis: Subcommittee on Motor Neuron Diseases/Amyotrophic Lateral Sclerosis of the World Federation of Neurology Research Group on Neuromuscular Diseases and the El Escorial 'Clinical limits of amyotrophic lateral sclerosis' workshop contributors. J Neurol Sci 1994;124 (suppl):96-107.

>38 Allen KD, Kasarskis EJ, Bedlack RS, Rozear MP, Morgenlander JC, Sabet A, et al: The National Registry of Veterans with amyotrophic lateral sclerosis. Neuroepidemiology 2008; 30:180-190.

39 Beghi E, Logroscino G, Chio A, et al: The epidemiology of ALS and the role of population-based registries. Biochim Biophys Acta 2006;1762:1150-1157.

40 National registry offers new hope for ALS. Lancet Neurol 2009;8:1.

41 Worms PM: The epidemiology of motor neuron diseases: a review of recent studies. J Neurol Sci 2001;191:3-9. 